Investigaciones Fenomenológicas, n. 9, 2012, 89-115. e-ISSN: $1885-1088$

\title{
El "viraje" en los "Beiträge" de M. Heidegger Y en los manuscritos C de E. Hussert
}

\author{
Roberto J. Walton \\ Universidade de Buenos Aires, Argentina \\ grwalton@fibertel.com.ar
}

Resumen: El artículo considera en primer lugar el papel asignado por Heidegger, en su análisis del viraje (Kehre), al acontecimiento-apropiación (Ereignis) como el punto medio entre el ser y el Dasein. En el carácter abismal de la oscilación entre el llamado del primero y la pertenencia del segundo reside la unidad originaria del tiempo-espacio que deja emerger ambos momentos hacia su separación. Esto permite a su vez el despliegue de un tiempo derivado y un orden para la medición. En segundo lugar, se intentan encontrar puntos de vista similares en los análisis de Husserl sobre la temporalidad. Así, al abismo del ser corresponde un horizonte inicial originario; al tiempo-espacio abismal, la pretemporalización de una protohyle de la mano con kinestesias espacializantes; a la proyección del Dasein para captar la oscilación mediante una contraoscilación, el volverse del yo hacia la prototemporalización; a la separación del tiempo a partir del abismo, la constitución de las distinciones temporales; y a la derivación del orden del tiempo, la constitución del tiempo como forma. En tercer lugar, se expone la noción heideggeriana de decisión respecto de la pertenencia o no-pertenencia al ser a fin de criticar una parte componente de la historia del ser, esto es, la posición. En cuarto lugar, el artículo se ocupa de la noción husserliana de decisión en tanto ligada a la institución de un horizonte histórico. Por último, se destacan semejanzas y diferencias entre las nociones de acontecimiento-apropiación y presente viviente en la medida en que ambas desempeñan el mismo papel en la búsqueda de un nivel último que hace posible todo.

Palabras clave: Viraje, acontecimientoapropiación, abismo, tiempo, protohorizonte, volverse-hacia, decisión, presente viviente.

\begin{abstract}
The article first considers the role ascribed by Heidegger, in his analysis of turning (Kehre), to event or enowment (Ereignis) as the middle-point between Being and Dasein. In the abyssal character of the oscillation between the call of the former and the belonging of the latter lies the originary onefold of time-space that lets both moments emerge into their separateness. This enables in turn the development of a derivative time and an order for measurement. Second, an attempt is made to find similar views in Husserl's analysis of temporality. Thus, to the abyss or ab-ground of Being there corresponds a primal empty horizon; to the abyssal time-space, the pretemporalization of a primal hyle hand-to-hand with spatializing kinestheses; to Dasein's projection to get hold of the oscillation in a counter-oscillation, a turning of the ego to a primal temporalization; to the separation of time out of the abyss, the constitution of temporal distinctions; and to the derivation of an order for measurement, the constitution of time as a form. Third, Heidegger's notion of a decision regarding the belongingness or nonbelongingness to Being is set forth in order to criticize a component part of the history of Being, i.e., positing. Fourth, the article deals with Husserl's notion of decision as tied to the institution of a historical horizon. Finally, similarities and differences are shown between the notions of event and living present insofar as they both play the same role in the search for an ultimate level that renders everything possible.
\end{abstract}

Palabras clave: Turning, event (enownment), abyss, time, primal horizon, turning-toward, decision, living present. 


\section{SOLIPSISMO Y FENOMENOLOGÍA TRANSCENDENTAL}

Hay un problema que ha sobrevolado como un espectro las teorías fenomenológicas de la intersubjetividad. Me refiero al problema del solipsismo. Desde que, en el primer párrafo de la quinta meditación cartesiana, Edmund Husserl dirigió un argumento solipsista contra su propia fenomenología trascendental, interpretada como un idealismo, ésta no ha cesado de tener que confrontarse con y explicarse ante esa objeción. En los términos de su formulación husserliana, la objeción solipsista está contenida por entero en una perplejidad que tiene su raíz en la propia posición reflexiva instauradora de la fenomenología:

Cuando yo, el yo que medita, me reduzco a mi ego trascendental absoluto mediante la epoché fenomenológica, ¿no me convierto en un solus ipse y no permanezco como tal en cuanto que yo, bajo el título Fenomenología, ejerzo consecuentemente una autoexplicitación? ¿No deberá una fenomenología, que quiere resolver los problemas del ser objetivo y presentarse como Filosofía, ser estigmatizada como solipsismo trascendental ${ }^{1}$

El trabajo esboza en primer lugar los lineamientos de la noción de viraje, y su relación con un tiempo que se propone al Dasein, tal como Martin Heidegger explicita la cuestión en sus Beiträge zur Philosophie. Luego intento mostrar una situación análoga en Edmund Husserl, en especial en sus manuscritos tardíos sobre el tiempo, en virtud de la recepción de una pretemporalidad anterior a las operaciones del yo. Un isomorfismo gira en torno de una temporalidad primigenia que tiene su lugar o bien en un abismo o bien en un horizonte inicial originario. En pasos sucesivos examino las dos respuestas elaboradas ante la interpelación recibida. Las divergencias se relacionan aquí con el tipo de decisión en favor de una temporalidad. Por último, examino analogías entre las nociones de Ereignis y presente viviente como dos interpretaciones de una instancia última en la fenomenología. Respecto de la temporalidad primigenia, la respuesta a su interpelación y la instancia última que opera entre una y otra encontramos términos que juegan un papel análogo en estructuras análogas. Estas conside-

\footnotetext{
1 "Wenn Ich, das meditierende Ich, mich durch die phänomenologische epoche auf mein absolutes transzendentales Ego reduziere, bin ich dann nicht zum solus ipse geworden, und bleibe ich es nicht, solange ich unter dem Titel Phänomenologie konsequente Selbstauslegung betreibe? Wäre also eine Phänomenologie, die Probleme objektiven Seins lösen und schon als Philosophie auftreten wollte, nicht als transzendentaler Solipsismus zu brandmarken?". Edmund Husserl, Gesammelte Werke-Husserliana ILX, Dordrecht, Springer (con anterioridad: Den Haag, Martinus Nijhoff; Dordrecht / Boston / London, Kluwer Academic Publishers), 1950-2009, Hua I, p. 91.
} 
raciones conducen a moderar la afirmación de Heidegger: "Mi pregunta por el tiempo se determinó a partir de la pregunta por el ser. Ella marchó en una dirección que ha permanecido siempre extraña a las investigaciones de Husserl sobre la conciencia interna del tiempo"².

\section{El Viraje en Heidegger: el llamado de la temporariedad}

En el "Seminario en Le Thor 1969", Heidegger señala que el significado de la noción de "sentido del ser" en Ser y tiempo se volvió insuficiente porque era comprendida desde el ámbito del proyecto o proyección del Dasein ${ }^{3}$. El inconveniente de este punto de partida reside en que sugiere entender el proyecto como operación humana. Con posterioridad a Ser y tiempo, Heidegger sustituye la expresión "sentido del ser" por la expresión "verdad del ser" para expresar el viraje desde el enfoque trascendental a la perspectiva de la historia del ser. Según esta perspectiva, el Dasein ha de responder al llamado (Zuruf) del ser. En el medio del ser y del Da-sein, el Ereignis o acontecimiento apropiante lleva al Dasein a lo que tiene de propio por medio del ser, y a la vez lleva al ser a lo que tiene de propio por medio del Dasein. Tal acontecer es el eje de un contrabalanceamiento (Gegenschwingung) o recíproca oscilación que tiene el carácter de un viraje (Kehre). Se trata de un giro que tiene lugar en el plano de los fenómenos y que se refleja en el llamado viraje en el pensar por el cual importa más el movimiento que va del ser al Dasein que el movimiento por el cual el Dasein se trasciende en dirección al ser. Por eso Heidegger afirma que "[el] Ereignis tiene su más íntimo acaecer y su más amplio alcance en el viraje" ${ }^{\prime 4}$.

En un movimiento de correspondencia que responde a un llamado o interpelación, el Dasein se ensambla en aquello que posibilita su comportamiento, y que, si bien no está a su disposición, él contribuye a poner de manifiesto. La proyección del Da-sein arrojador o proyectante (Werfer) resulta ser una proyección arrojada (geworfen) porque es llevada a lo que tiene de propio a partir

\footnotetext{
2 Martin Heidegger, "Über das Zeitverständnis in der Phänomenologie und im Denken der Seinsfrage", en Eugen Fink / Martin Heidegger / Ludwig Landgrebe / Max Müller y Herman L. Van Breda, Phänomenologie, lebendig oder tot?, Karlsruhe, Badenia, 1969, p. 47.

${ }^{3}$ Martin Heidegger, Seminare (1951-1973), Frankfurt am Main, Vittorio Klostermann, 1986, p. 335.

4 Martin Heidegger, Beiträge zur Philosophie (Vom Ereignis) (1936-1938), Frankfurt am Main, Vittorio Klostermann, 1989, p. 407.
} 
de un llamado que es entendido también como una yección o arrojarse a (Wurf, Zuwurf) por parte del ser. La proyección es a la vez una experiencia de la condición-de-arrojado (Geworfenheit) y de la pertenencia (Zugehörigkeit) al ser. El hombre pertenece al ser y corresponde a la interpelación en un viraje (Kehre), y el ser necesita del hombre y lo interpela en un contra-viraje (Wider-kehre). De modo que el viraje se despliega "entre el llamado-a (al perteneciente) y la pertenencia (de lo que es llamado)" ${ }^{\prime 5}$. Según la expresión de F.-W. von Herrmann, la yección aconteciente y apropiante del ser tiene su reverso en una proyección acontecida y llevada a lo propio del hombre. La yección da lugar a la proyección, y la proyección complementa la yección ${ }^{6}$. Heidegger escribe: "Este contrabalanceo (Gegenschwung) entre el necesitar y el pertenecer constituye el Ser como Ereignis, $[\ldots]^{\prime \prime 7}$. La contraoscilación en la conjunción de llamado y pertenencia es el Ereignis mismo, y Heidegger aclara respecto de la conjunción: "El Ereignis es el medio que se establece y se mediatiza a sí mismo (die sich selbst ermittelnde und vermittelnde Mitte) y al que todo esenciar de la verdad del Ser (Seyn) debe ser retrotraído en el pensar"8.

Una vez considerado el Ereignis como término medio entre ser y Dasein se debe examinar el carácter de abismo del ser. Heidegger señala que el ser esencia o se despliega, y se desoculta, como abismo no solo porque carece de fundamento sino también porque se sustrae como fundamento del ente. Mientras el Dasein no proyecte el ser de tal modo que el ser pueda desplegarse como el fundamento del ente, el ser acaece como abismo y no como fundamento pleno, o, con otras palabras, acaece como fundamento incipiente o "protofundamento (Urgrund)" o "quedar a un lado del fundamento". Por tanto, en el abismo, el fundamento "aún funda y sin embargo no funda propiamente" ${ }^{9}$. El ser solo esencia o se despliega como fundamento cuando el Dasein puede responder a

5 Ibidem, p. 407. Cfr. pp. 65, 239. Cfr. Martin Heidegger, Wegmarken (1919-1961), Gesamtausgabe 9, Frankfurt am Main, Vittorio Klostermann, 1976, pp. 341, 348.

${ }^{6}$ Cfr. Friedrich-Wilhelm von Herrmann, Wege ins Ereignis. Zu Heideggers Beiträge zur Philosophie, Frankfurt am Main, Vittorio Klostermann, 1994, pp. 30ss., 92ss., 240s., 384s.; y Wahrheit. Freiheit. Geschichte: Eine systematische Untersuchung zu Heideggers Schrift, Vom Wesen der Wahrheit', Frankfurt am Main, Vittorio Klostermann, 2002, pp. 215ss. Una muy clara explicitación de los aspectos temporales de la yección y la proyección se encuentra en Ángel Garrido-Maturano, "El abismo y el tiempo. Elucidación de la noción de abismo y de temporalidad en los Beiträge zur Philosophie de Martin Heidegger", Revista Venezolana de Filosofía 36-37 (1999) 163-191.

7 Martin Heidegger, Beiträge zur Philosophie, p. 251.

${ }^{8}$ Ibidem, p. 73. Cfr. p. 262. Heidegger señala que "ser (Sein) y Ser (Seyn) son lo mismo y sin embargo fundamentalmente distintos" (Ibidem, p. 171). El término "Seyn" se atiene al giro en tanto que el término "Sein" queda atado a la perspectiva trascendental del primer período. Cuando Heidegger utiliza el término Seyn, lo traducimos con mayúscula.

${ }^{9}$ Ibidem, pp. 379s. 
la yección, es decir, "tomar al vuelo la contraoscilación de la apropiaciónaconteciente (den Gegenschwung der Er-eignung aufzufangen), ingresar en esta contraoscilación, y tan solo así llegar a ser sí mismo él mismo: el guardián de la proyección arrojada, el fundador fundado del fundamento" ${ }^{10}$.

Al análisis del Ereignis como punto medio entre el ser y el Dasein, y del abismo del ser, se añade el examen del desplegarse y desocultamiento o verdad del abismo como el tiempo-espacio que "es inherente a la verdad en el sentido de la esenciación del ser como Ereignis"11. Heidegger señala que el abismo "funda como la unidad de temporalización y espacialización", se refiere al tiempo-espacio como "esenciación del fundamento abismal", y lo asocia con "las trayectorias virantes (Kehrungsbahnen) del Ereignis, del viraje entre pertenencia y llamado, [... $]^{112}$. En virtud del contrabalanceo de ser y Dasein, la temporariedad (Temporalität) inherente a la verdad del ser coloca la temporalidad (Zeitlichkeit) extática analizada en Ser y tiempo bajo su despliegue. La temporariedad es recogida y asumida por la temporalidad. De modo que esta es "la indicación y la resonancia"13 de aquélla. Heidegger afirma que "el Da-sein, virando, es apropiado (ereignet) al Ereignis como esenciar del Ser y solo gracias a este origen como fundación del tiempo-espacio ('temporariedad') puede estar en situación de transformar la indigencia del abandono del ser $[\ldots]^{\prime 14}$. Por tanto, el abismo se despliega y funda como la unidad originaria de tiempo y espacio, y esta unidad se despliega desde el Ereignis como "aquello desde donde el fundamento es fundamento"15. Así, desde el entre que hace oscilar el llamado y la pertenencia, "se abre el Ereignis y llega a ser efectuable la proyección del origen de tiempo-espacio como unidad originaria desde el abismo del fundamento"16.

Heidegger procura una "interpretación originaria del tiempo" que pone de relieve "el ámbito en que el tiempo accede a la más extrema diferencia y de

\footnotetext{
${ }^{10}$ Ibidem, p. 239. "El arrojador mismo, el Da-sein, es arrojado, acontecido apopiadoramente (ereignet) por el Ser. [...] En tanto el arrojador proyecta y abre la patencia (Offenheit), se desvela, por medio de la apertura (Eröffnung), que él mismo es el arrojado, y que no efectúa otra cosa que tomar al vuelo la contraoscilación en el ser, esto es, ingresar en ella y de ese modo en el Ereignis, y solo así llegar a ser él mismo, a saber, el guardia del proyecto arrojado" (Ibidem, p. 304).

${ }^{11}$ Ibidem, p. 372.

12 Ibidem, pp. 383, 375, 372.

${ }^{13}$ Ibidem, p. 74.

${ }^{14}$ Ibidem, p. 18.

${ }^{15}$ Ibidem, p. 383. Cfr. pp. 17, 243, 375, 379.

${ }^{16}$ Ibidem, p. 385.
} 
este modo justamente a la intimidad del esenciarse con el espacio"17. A la verdad o desocultamiento del ser es inherente el tiempo-espacio respecto del cual nociones como cercanía y lejanía, o plenitud y vacío, no tiene el sentido que es inherente a las representaciones habituales del tiempo y el espacio. El abismo es un vacío, no en el sentido de una no-ocupación sino en el de un originario entreabrirse que a la vez es un rehusarse que interpela y suscita un salto del Dasein hacia el ser en medio del oscilante viraje del Ereignis: "El abismo es la unidad originaria de espacio y tiempo, aquella aunante unidad (einigende Einheit) que los deja disgregarse inicialmente en su separarse"18.

Para nombrar el modo en que desde el abismo acaece "la disgregación de espacio y tiempo", Heidegger se refiere a "transplazamientos (Verrückungen)"19 que asumen dos modalidades. Por un lado, el transplazamiento del tiempo se denomina "desplazamiento" (Entrückung) y es el acaecer que conserva lo que ha sido y anticipa lo que ha de venir. Mediante este desplazamiento, la temporariedad se disgrega en tres modos que se conjugan con los éxtasis temporales del Dasein, es decir, el futuro, el haber sido y el presente. El tiempo se da desde el abismo en tres modos esenciales, y el Dasein responde a través de los tres éxtasis temporales. Por otro lado, el transplazamiento del espacio se llama "emplazamiento (Berückung)" y es el acontecer por el cual el tiempo-espacio se conjuga con la espacialización acontecida del Dasein. Un demorarse del tiempoespacio al mantenerse en un instante hace surgir una espacialización u ordenamiento espaciante (Einräumung) en un sitio: "El tiempo-espacio como la unidad de la originaria temporalización y espacialización es él mismo originariamente el instante-sitio [... $]^{\prime 20}$. Así, según Heidegger, el abismo se ensambla en un tiempo-espacio que, en razón de que desplaza temporalmente y emplaza espacialmente, tiene el carácter de un sostén (Umhalt) que reúne las dimensiones del tiempo, y de una reunión (Sammlung) que se sustenta en un sitio y un instante. Lo que originariamente unifica al espacio y al tiempo es lo que los hace surgir a la vez en una indisoluble remisión recíproca. Este surgir no es un desgarro o fisura que suelta (Losriss) porque ni el desplazamiento es una dispersión de los éxtasis del tiempo ni el emplazamiento es la enajenación del ins-

\footnotetext{
17 Ibidem, p. 74.

${ }^{18}$ Ibidem, p. 379. Cfr. pp. 17, 243, 375, 383.

${ }^{19}$ Ibidem, pp. 373, 381.

${ }^{20}$ Ibidem, p. 384.
} 
tante-sitio del tiempo. Por tanto, el desplazamiento se muestra como una reunión sobre el sostén del emplazamiento, y el emplazamiento se muestra como un sostén para la reunión inherente al desplazamiento.

Tiempo y espacio se disgregan desde el abismo en que están enlazados. Así, el tiempo-espacio (Zeit-Raum) se convierte en espacio o lapso de tiempo (Zeitraum). Se torna "espacioso (geräumig)" y puede ser medido. Esta es una determinación del tiempo mismo que ya no pertenece al esenciar originariamente unido del tiempo-espacio. De ese modo se hace surgir el tiempo-espacio en el ente. Se puede hablar entonces de la separación entre dos puntos ahora del tiempo calculado. Así decimos que en el lapso de tiempo de 50 años sucedió esto o aquello. El tiempo es representado como el uno-tras-otro o sucesión de la serie de los ahoras y el espacio como el uno-junto-a otro en la coexistencia de lugares. El tiempo-espacio precede a los espacios particularizados y a los tiempos que transcurren. Tanto la dimensionalidad del tiempo (antes-después) como la del espacio (arriba-abajo, izquierda-derecha, adelante-atrás) "surgen a partir del abrigo de la verdad y, por tanto, del tiempo-espacio en el ente [...] Solo cuando algo que está ahí delante es sujetado y fijado surgen el flujo del 'tiempo' que pasa fluyendo por él y el 'espacio' que lo rodea"21. Frente al "simple y nunca calculable Ereignis de todo tiempo-espacio", Heidegger procura mostrar cómo "espacio y tiempo se convierten en representaciones de marcos en el camino de su interpretación con respecto al mégethos ${ }^{\prime 22}$. El tiempo como marco es una forma de orden que permite introducir distinciones en el ente a través del número de lo mudable y lo contable. Un ejemplo de estos marcos de ordenamiento para lo que está ahí delante, y para determinación de su magnitud, se encuentra en las formas kantianas de la intuición. El vacío es entonces lo no-ocupado en las formas. En relación con este plano derivado, Heidegger puede afirmar que "el originario esenciar del tiempo, al igual que el del espacio, no accede para nada a la experiencia"23.

Cinco momentos se relacionan, pues, con el tiempo: 1) el abismo del ser como su origen; 2) el tiempo-espacio inherente al abismo; 3) la fundación del ahí implicada en la contraoscilación del Dasein; 4) la disgregación del espacio y

${ }^{21}$ Ibidem, p. 382. Cfr. Martin Heidegger, Zur Sache des Denkens (1962-1964), Gesamtausgabe 14, Frankfurt am Main, Vittorio Klostermann, 2007, pp. 14, 18s.

${ }_{22}$ Martin Heidegger, Beiträge zur Philosophie, pp. 409, 173.

${ }^{23}$ Ibidem, p. 223. 
el tiempo a partir del espacio-tiempo; y 5) la derivación de un espacio o lapso de tiempo medible según los patrones de la representación de marcos para la determinación del tiempo. Para estos momentos he de buscar ahora un paralelo en Husserl.

\section{El VirAJE EN HuSSERL: EL LLAMAdO DEL CURSO PRIMIGENiO}

Al referirse al basamento de los actos, Husserl describe un horizonte inicial originario que cumple la función del abismo heideggeriano porque se sitúa en el origen de la temporalización y de la espacialización y es un horizonte vacío porque aún no interviene en él la intencionalidad:

\footnotetext{
El yo tiene ya el "horizonte de mundo" -el horizonte inicial originario en el que nace implícitamente el horizonte de mundo humano, así como, en el protocomienzo de la temporalización (Uranfang der Zeitigung), ya está implicado el horizonte de la temporalización como temporalización en la que se encuentra implicada una y otra vez una nueva temporalización y así todo está implicado en su lugar en todo lo en sí anterior. El protohorizonte, la masa hereditaria, es en su sentido primigenio horizonte vacío. ${ }^{24}$
}

Husserl complementa las descripciones sobre la conciencia interna del tiempo con un análisis que pone al descubierto una dimensión temporal preyoica del sujeto, esto es, la sustentación del ámbito del yo en un fluir originario y pasivo y en una intencionalidad instintiva que orienta el fluir. Se ocupa de una "temporalización intersubjetiva en el pretiempo intersubjetivo" ${ }^{25}$ porque el presente primigenio de cada yo depende de una temporalización intersubjetiva que se extiende a todos los yoes y cuya protensión remite en cuanto anticipación a una habitualidad originaria. Esto significa que el tiempo subjetivo está precedido por una pretemporalización que se despliega en el plano de una protointersubjetividad a la que se debe la primigenia institución de la coexistencia. En un manuscrito bajo título: "Teleología universal. El impulso intersubjetivo, que abarca a todos y a cada uno de los sujetos, visto trascendentalmente ${ }^{\prime 26}$, Husserl se refiere a la primordialidad como un sistema de impulsos que contiene impulsos orientados hacia otros cursos de vida y afirma

24 Edmund Husserl, Zur Phänomenologie der Intersubjektivität. Texte aus dem Nachlass. Dritter Teil: 1929-1935, Husserliana XV, Den Haag, Martinus Nijhoff, 1973, p. 604.

${ }^{25}$ Ibidem, p. 597.
${ }^{26}$ Ibidem, p. 731. 
En mi vieja teoría de la conciencia interna del tiempo he tratado la aquí mostrada intencionalidad precisamente como intencionalidad que se dirige hacia delante como protensión y se modifica como retención, pero que conserva unidad, pero no he hablado del yo, no la he caracterizado como intencionalidad yoica (en el más amplio sentido como intencionalidad de la voluntad). Más tarde he introducida esta última como fundada en una intencionalidad sin yo ("pasividad"). ${ }^{27}$

Tenemos aquí un doble giro orientado, más allá de la conciencia interna del tiempo, hacia la intencionalidad del yo y su voluntad y hacia la intencionalidad sin yo. Se trata de una doble orientación hacia la actividad y hacia la pasividad. Respecto de la pasividad, Husserl pregunta a continuación:

¿Acaso no tenemos el derecho o no debemos presuponer una intencionalidad impulsiva universal que compone unitariamente cada presente primigenio como temporalización permanente y que de un modo concreto sigue impulsando de presente en presente, [...] de tal suerte que, en cada presente primordial, impulsos de nivel superior, que trascienden, se extienden dentro de todo otro presente y enlazan a todos unos con otros como mónadas, a la par que todas están implicadas una en otra -intencionalmente? ${ }^{28}$

Así, la intencionalidad instintiva tiene una función vinculante sobre la cual se asienta un entramado temporal de diversos cursos singulares.

El yo trascendental es sujeto de un "instinto trascendental" que se muestra como "la tendencia universal que pasa a través de la totalidad de la intencionalidad del ego"29. En un nivel preyoico, Husserl describe una intencionalidad instintiva que está en la base de toda constitución de la naturaleza, toda acción humana y toda relación con el otro. La tarea de retroceder a la dimensión originaria de la subjetividad conduce a la protosensibilidad de un preyo, dotado de habitualidades originarias o instintivas que operan con anterioridad a las habitualidades que provienen de los actos y son adquiridas por el yo a lo largo de su vida. Husserl señala que "protoinicialmente el yo está en el instinto con horizonte vacío" ${ }^{30}$, y caracteriza el impulso instintivo como "la preforma de la preposesión (die Vorform der Vorhabe)", y la satisfacción del impulso como "la preforma del auténtico acto (die Vorform des eigentlichen Aktes) ${ }^{\prime \prime 31}$. En la medida en que se traduce en sistemas kinestésicos e implica un principio de aso-

${ }^{27}$ Ibidem, p. 594 s.

${ }^{28}$ Ibidem, p. 595.

${ }^{29}$ Edmund Husserl, Späte Texte über Zeitkonstitution (1929-1934). Die C Manuskripte, Husserliana - Materialien VIII, Dordrecht, Springer, 2006, p. 260.

${ }^{30}$ Ibidem, p. 283.

${ }^{31}$ Ibidem, p. 326. 
ciación de las afecciones, el impulso instintivo configura una disposición originaria del yo en virtud de la cual se encuentra "predelineada para mí la constitución del mundo" ${ }^{\prime 32}$.

Husserl se refiere a dos presupuestos de la constitución:

[...] la constitución del ente de diferentes niveles, de mundos, de tiempos, tiene dos protopresupuestos, dos protofuentes, que, hablando temporalmente (en cada una de estas temporalidades), siempre "subyacen" a ella: 1) mi yo primigenio como operante, como protoyo en sus afecciones y acciones, con todas sus estructuras esenciales en los modos pertinentes; y 2) mi no-yo primigenio como curso primigenio de la temporalización y él mismo como protoforma de la temporalización que constituye un campo temporal, el de la protomaterialidad. Pero ambos protofundamentos están unidos, son inseparables, y, por tanto, si se los considera por separado, son abstractos. ${ }^{33}$

Husserl investiga un protonivel (Urstufe) anterior a cualquier tipo de constitución aperceptiva y lo refiere, del lado del ego, a protokinestesias (Urkinästhese) y protosentires (Urgefühle) dirigidas de una manera indiferenciada a una protohyle (Urhyle) también indiferenciada que llena todo el curso de vivencias: "La protohyle con las prokinestesias. Decimos: un 'obrar' unitario y carente de meta, a una con una totalidad no separada de la hyle (eine ungeschiedene Totalität der Hyle $)^{\prime 34}$. Se trata de una totalidad hylética teñida por sentimientos y motivada por movimientos corporales. A estos tres protomomentos fusionados -hyle, sentimiento, kinestesia- se añade una dependencia del instinto que, del lado del yo, condiciona los movimientos y sentimientos, y, del lado extraño al yo, organiza la formación de unidades hyléticas. Además, una prototemporalización opera a través de ambos lados en un presente protomodal que actúa como un medio que se establece y se mediatiza al modo del Ereignis.

En lo que concierne al lado no-yoico, Husserl se ocupa de "la protointencionalidad pasiva, la de la temporalización pasiva de unidades, respecto de la cual no se puede hablar de objetos $[\ldots]^{\prime \prime 35}$, esto es, "la prototemporalización en que un cuasi-mundo hylético extraño al yo (eine ichfremde hyletische Quasi-Welt) tiene su preser (Vor-sein)" ${ }^{\prime 36}$. Y afirma: "La protohyle en su propia temporalización es el núcleo por así decirlo extraño al yo en el presente concreto"37. La indiferenciación de lo no-yoico y lo yoico transcurre en un pretiempo (Vorzeit)

\footnotetext{
32 Edmund Husserl, Zur Phänomenologie der Intersubjektivität III, p. 385.

${ }^{33}$ Edmund Husserl, Späte Texte über Zeitkonstitution, p. 199. Cfr. pp. 100, 110, 118, 188 s.

${ }^{34}$ Ibidem, p. 225. Cfr. p. 99.

${ }^{35}$ Ibidem, p. 335.

${ }^{36}$ Ibidem, p. 350

37 Ibidem, p. 110.
} 
que no es aún una forma de objetos para el preyo (Vorich) que vive en este curso de conciencia. Y en lo que atañe al lado yoico, o más bien pre-yoico, se encuentra ahí "el ego para el cual existe este premundo (Vor-Welt), y a través del cual, o a través del funcionamiento del cual, en la afección y acción, el mundo en sentido propio (die eigentliche Welt) llega a la creación, en una pluralidad de niveles de creación, a los que corresponden mundos relativos (relative Welten $)^{\prime \prime 38}$.

Husserl afirma que el "no-yo protofluyente y protoconstituyente" exhibe un "protoacontecer temporalizante-temporalizado" junto al cual se encuentra el yo en tanto afectado de modo que tiene "una temporalización paralela precisamente según la forma para los actos"39. Así como el Dasein se vuelve hacia la temporariedad en el abismo del ser y la acoge en su temporalidad, el yo se vuelve hacia la pretemporalización en el abismal cuasi-mundo hylético extraño al yo y la convierte en temporalización. La pretemporalización consiste en el constante desvanecerse de la experiencia en un continuo entramado de modificaciones sin que haya aún intenciones temporales en sentido propio: "¿Qué clase de "intencionalidad" es ésta que circula bajo la bandera de la "retención"? ¿Es propiamente una intencionalidad? Un constante uno-en-otro de la modificación, del de $[\ldots]$, de, etc., tengo yo; pero falta sin embargo la auténtica intención $^{\prime 40}$. La temporalidad subyoica opera como una yección aconteciente y temporalizante que es asumida por el yo en una proyección acontecida para dar lugar a distinciones temporales. El curso primigenio en su indiferenciación cumple el papel de la temporariedad heideggeriana porque como fenómeno que se gesta en la pasividad significa un llamado que afecta al yo y motiva una respuesta: "Éste será entonces por su parte el presupuesto (como llamado ( $A n$ ruf), interpelación (Anspruch)) para el acto del yo como 'respuesta' (conciencia en sentido estricto)" ${ }^{41}$. Así, Husserl describe un "volverse" del yo "hacia" (Zuwendung) lo que lo afecta como "el acto de respuesta", esto es, como un operar "sobre el fundamento de contenidos que siempre anteceden"42 para continuar un proceso temporal que no emana primariamente de él sino de lo que le es extraño, es decir, de la hyle difusa. Con el volverse del yo se produce, en la

\footnotetext{
${ }^{38}$ Ibidem, p. 350. Cfr.. p. 269.

${ }^{39}$ Ibidem, p. 200.

${ }^{40}$ Ibidem, p. 122.

${ }^{41}$ Ibidem, p. 191. Cfr. pp. 192, 351

${ }^{42}$ Ibidem, pp. 326, 350.
} 
indiferenciación inicial, una diferenciación de intenciones temporales que luego puede ser explicitada en la reflexión por la cual "no solo vivencio la transformación retencional sino que en ella ejercito un captar y conservar en sentido yoico", de modo que, al tematizar la vida que fluye, "efectúo precisamente con ello una auténtica temporización (eine eigentliche Verzeitigung) ${ }^{43}$. La intervención yoica no consiste solamente en acompañar y explicitar la condición temporal de lo no-yoico. Además, el yo "tiene en sí un modo de temporalización" independiente de la pretemporalización hylética en tanto puede mantener captado lo que transcurre, con lo cual introduce "una doble retención" con "la retención yoica de la 'validez'"144. Así se inicia, en la constitución del tiempo, una participación cada vez más fuerte del yo que habrá de ser tratada más adelante.

Análogamente, en relación con la espacialización descrita por Heidegger, el horizonte inicial originario se asocia con kinestesias que tiene su raíz en una masa hereditaria de instintos y cuya diferenciación posibilita la constitución de una espacialidad cada vez más compleja de acuerdo con los movimientos de los ojos, la cabeza, el tronco y el andar. En el estadio inicial, en una suerte de tiempo-espacio, están fusionados un pre-tiempo, que posibilitará la constitución del tiempo, y protokinestesias, que darán lugar a la constitución del espacio. Así, el horizonte inicial se muestra como un abismo en el que no hay todavía distinciones. Reiterando la argumentación de Heidegger, se lo puede considerar fundante porque el tiempo y el espacio emergen de él, pero no lo es propiamente en virtud de esa indiferenciación. Solo puede ser considerado como un fundamento una vez que se constituye la espacialidad y la temporalidad. Además, si analizamos el movimiento kinestésico, advertimos una convergencia de tiempo y espacio ligada a los movimientos del cuerpo propio. Respecto de su unidad con el tiempo, se puede recordar que el sistema kinestésico se actualiza

43 Edmund Husserl, Zur phänomenologischen Reduktion. Texte aus dem Nachlass (1926-1935), Husserliana XXXIV, Dordrecht/Boston/London, 2002, p. 184. Este texto corresponde también a un manuscrito del grupo $C$. Sobre la cuestión son ilustrativas las siguiente afirmaciones: "La investigación más minuciosa de la diferencia entre una temporalización efectuada yoica y activamente por un lado y una temporalización hylética que acaece anónima y pasivamente por otro lado conduce finalmente a Husserl en los Manuscritos $\mathrm{C}$ tan lejos que él niega toda operación constitutiva originaria al protocurso que transcurre sin participación alguna del yo. Por tanto, solo si existe una operación yoica, se podría hablar de una constitución de objetos temporales. Solo por medio de la efectuación posterior de un acto yoico de reflexión sobre el protoproceso preintencional, esto es, sobre la base de una eficaz modificación de la esencia del protoproceso se origina para este protocurso hylético un significado constitutivo" (Rudolf Bernet y Dieter Lohmar, "Einleitung der Herausgeber", en Edmund Husserl, Die Bernauer Manuskripte über das Zeitbewusstsein (1917/18), Husserliana XXXIII, Dordrecht/Boston/London, Kluwer Academic Publishers, 2001, p. xxxvii).

${ }^{44}$ Edmund Husserl, Späte Texte über Zeitkonstitution, pp. 198, 201. 
en un movimiento que no solo posibilita el espacio sino que a la vez reúne al tiempo. En cada momento del movimiento están contenidos los precedentes y los que se sucederán hasta su término. Esto significa que en cada momento parcial de un movimiento se encuentra anticipado protensionalmente y conservado retencionalmente un despliegue temporal y a la vez contenido potencialmente un despliegue espacial. Así, el sistema kinestésico con su horizonte potencial participa de las características del abismo heideggeriano en tanto posibilita la disgregación de espacio y tiempo. Por otro lado, es a la vez una reunión y un sostén en la medida en que el mundo percibido es un correlato de sus potencialidades. Por eso Merleau-Ponty dice, poniendo de relieve lo implícito en el análisis de Husserl sobre las kinestesias, que el cuerpo propio "habita el espacio y el tiempo" de modo que no se encuentra en ellos sino que "se aplica a ellos y los abraza" ${ }^{45}$. La relación entre el movimiento corporal y el surgimiento de la experiencia del tiempo ha sido puesta de relieve por L. Landgrebe ${ }^{46}$. Sin embargo, una omisión en su análisis, que, por lo demás es muy valioso para el lado yoico, reside en que, en el caso de Husserl, la convergencia de temporalidad y movimiento kinestésico, es decir, del tiempo-espacio, no implica una cooriginariedad porque el tiempo no pierde una preeminencia. Ésta se asocia con su presencia no solo en el lado yoico sino también en el lado extraño al yo.

Con la temporalización, en el fluir de las maneras de darse temporales, se conserva un estilo de darse que consiste en la articulación de impresiones, retenciones y protensiones, y correlativamente del presente, el pasado y el futuro, como una "forma rígida"47. Esta forma del fluir no fluye, aunque sí fluye la forma plenificada con un contenido. A las distinciones temporales y a la conservación de una forma en las distinciones se suma una unificación de los tiempos. Que todos los tiempos particulares se unifiquen por medio de una asociación formal se debe a que constituyen noéticamente el único tiempo de la vida protoconstituyente, de modo que todos los tiempos de todos los objetos se encuentran en una relación esencial con el prototiempo del presente viviente: "Él mismo es la unidad de una fusión asociativa en la cual un único tiempo, que es

${ }^{45}$ Maurice Merleau-Ponty, Phénoménologie de la perception, Paris, Gallimard, 1945, pp. 162, 164.

$46 \mathrm{Cfr}$. Ludwig Landgrebe, "Phänomenologische Analyse und Dialektik", Phänomenologiesche Forschungen, 10, Freiburg, Karl Alber, 1980, pp. 74-87.

${ }^{47}$ Edmund Husserl, Späte Texte über Zeitkonstitution, p. 63. Cfr. pp. 58, 178. 
la forma de toda temporalización, se temporaliza a sí mismo y temporaliza o constituye objetos, onta temporales, con su respectivo tiempo, $[\ldots]^{\prime \prime 48}$.

Husserl tiene su propia respuesta para la pregunta: "¿De dónde tiene el especializar y el temporalizar su propio origen y su separación?" ${ }^{\prime 49}$. En suma, encontramos las siguientes correspondencias entre Husserl y Heidegger: 1) el horizonte inicial originario y vacío se relaciona con el abismo del ser; 2) la pretemporalización de la protohyle, unida a protokinestesias espacializantes, con el espacio-tiempo; 3) el volverse del yo hacia la pretemporalización hylética con el tomar al vuelo el Dasein la contraoscilación; 4) la constitución de distinciones temporales con la disgregación del tiempo a partir del abismo, esto es, del tiempo y el espacio desde el tiempo-espacio; y 5) la forma del tiempo con el espacio de tiempo como representación-marco.

\section{LA DECISIÓn En HEIDEgGeR: PERTENENCIA O NO-PERTENENCIA AL SER}

Debemos considerar ahora más de cerca los caracteres específicos que adquiere la respuesta al llamado del abismo o del horizonte inicial indiferenciado tomando primero nuevamente como guía indicaciones de Heidegger para considerar luego en un apartado ulterior la visión husserliana.

Heidegger afirma que "el esenciar del temporalizar" es "el desplazamiento hacia lo que se rehúsa" ${ }^{\prime 50}$, es decir, hacia el ser que se anuncia e interpela a la vez que se sustrae. El ser adviene al Dasein en el modo del rehusarse anunciando su ausencia como fundamento del ente. Este anuncio es un Ilamado, y, por tanto, significa un futuro en tanto implica la posibilidad de un arribo en que el ser se concede como fundamento del ente. El Dasein es desplazado hacia el futuro de un posible arribo en un aguardar (Erharren) que lo anticipa. Además, es desplazado hacia el haber-sido que sigue siendo en el recordar (Erinnern) su pertenencia al ser. Por último, es desplazado hacia el presente en el experienciar (Erfahren) el abandono del ser. Esta experiencia presente proviene del llamado del ser que hace asumir la pertenencia de modo que nos descubre el

\footnotetext{
${ }^{48}$ Ibidem, p. 296.

${ }^{49}$ Martin Heidegger, Beiträge zur Philosophie, p. 383.

50 Ibidem, p. 384.
} 
abandono del ser. Por eso el desplazamiento de la futuridad pone en movimiento la temporalización y tiene preeminencia entre los desplazamientos.

El tiempo nos desplaza hacia lo que, en otro texto, Heidegger llama la triplicidad y unidad de "lo equi-tempóreo (das Gleich-Zeitige)" ${ }^{\prime 51}$. A tres modos en que el tiempo originario, que aparece bajo la figura del tiempo-espacio, se arroja al Dasein corresponden tres modos correlativos de temporalización del Dasein. El Dasein proyecta tres modos de ser desplazado que resultan del acontecer en que se arrojan a él los tres desplazamientos en que la temporeidad se despliega en el abismo. Así, el darse del tiempo reposa en esta contraoscilación entre el aconteciente desplazamiento del tiempo originario y el acontecido ser desplazado del Dasein hacia el tiempo originario. Con referencia a este balanceo, Heidegger escribe: "El 'tiempo' debería ser experienciable como el espaciode-juego 'extático' de la verdad del Ser"52.

Experienciar el abandono del ser lleva a volverse hacia la pertenencia y de ese modo iniciar la superación del olvido del ser en una preparación de la situación histórica para el arribo del ser. Heidegger se refiere a "el presente dirigido y solo dirigido a la decisión: instante. En él están insertos los desplazamientos (sind die Entrückungen eingerückt), y él mismo esencia solo como la reunión (Sammlung) de los desplazamientos ${ }^{\prime 53}$. El instante es el presente en tanto en él se reúnen y acontecen conjuntamente los tres desplazamientos. El Dasein experiencia en el instante el abandono del ser que le sale al encuentro en mutua correlación con el estar a la espera del llamado del ser y con el recordar la pertenencia al ser. En el instante los tres desplazamientos del tiempo y los tres modos de ser desplazado el Dasein se dan unidos en una copertenencia mutua. La triple yección del tiempo originario se reúne en el instante de la proyección del Dasein, y en él se despliega el ámbito de la decisión acerca de si acontecerá o no el viraje:

El recordante aguardar (que recuerda una oculta pertenencia y aguarda un llamado del Ser) nos pone frente a la decisión (Entscheidung) acerca de si o de si-no respecto del arribo del Ser. Más precisamente, la temporalización (Zeitigung) [...] funda de un modo abismal (ab-gründigerweise) el ámbito de la decisión. ${ }^{54}$

\footnotetext{
${ }^{51}$ Martin Heidegger, Unterwegs zur Sprache (1950-1959), Gesamtausgabe 12, Frankfurt am Main, Vittorio Klostermann, 1985, pp. 201s.

52 Martin Heidegger, Beiträge zur Philosophie, p. 242.

53 Ibidem, p. 384.

${ }^{54}$ Idem.
} 
Heidegger afirma, pues, que una temporeidad incipiente es retomada por la temporalidad del Dasein para preparar el arribo del ser completando en el instante, mediante una decisión, el esbozo de tiempo que le es donado. En el intento de relacionar esta situación con la recepción husserliana de una pretemporalidad anterior a las operaciones del yo, es necesario mostrar a continuación que toda decisión respecto del ser, del olvido del ser o de una posible recuperación, están sujeta a un determinado a priori, y que la comprensión misma del ser tiene sus condiciones de posibilidad. Con otras palabras: se debe mostrar 1 ) una estructura invariante que rige toda comprensión del ser; y 2) la subordinación de la comprensión del ser a una estructura previa de carácter trascendental. La primera cuestión lleva a poner de relieve una peculiar característica en el intento heideggeriano de describir una historia del ser. La segunda cuestión conduce a hacer uso de una objeción que el mismo Husserl ha lanzado contra Heidegger.

Respecto del primer punto es necesario mostrar un rasgo del análisis heideggeriano que lo desplaza del marco de su propio planteamiento y posibilita el avance hacia una perspectiva husserliana. En relación con la historia del ser, puede sostenerse que Heidegger reconoce implícitamente un invariante que la recorre porque mantiene una misma estructura -la del poner (Stellen)- para el desvelamiento originario y para el desvelamiento bajo la im-posición de la técnica. En uno y otro caso encontramos el mismo movimiento. El ser fue experienciado por los primeros pensadores como phýsis, es decir, como el aparecer que aparece, como el surgir desde sí, como el venir a la presencia de lo presente. Pero lo que aparece en el aparecer muestra un aspecto o idéa que desde Platón se separa de su fundamento en el aparecer, se presenta como "la" interpretación del ser, y así inicia la confusión del ser con el ente. Heidegger recuerda que Aristóteles interpreta el eîdos o aspecto como una morphé o forma que se relaciona con una materia o hyle. El aspecto puede exhibirse en sí mismo como algo que aparece desde sí, o bien puede presentarse como un modelo o paradigma que debe efectivizarse en una materia adecuada. La morphé se relaciona con una poíesis, con una producción, porque la hyle es aquello a partir de lo cual se produce algo, por ejemplo, la madera como una materia para el eîdos de una mesa. Así, se interpreta el ente al modo de una mesa que el carpintero 
forma a partir de un modelo a través de "la configuración de la 'idea', del eîdos, en la hyle ${ }^{\prime \prime 55}$. Con esta interpretación del aspecto o morphé en términos de algo que es en y para una tékhne se inicia el camino a la reducción del ente a la condición de objeto y de objeto de encargo. El proceso "está preparado por el hecho de que la entidad está determinada a partir de la tékhne y por la idéa" ${ }^{\prime 56}$. El proceso se acentúa con la figura medieval del ente como ens creatum, es decir, como ente producido por el ente supremo. A ello siguen la figura cartesiana del ente como ens certum, o sea, el ente cuya verdad es producida por un sujeto que tiene certeza de su existencia y sus determinaciones, y la figura kantiana del ente como ens objectivum, esto es, el ente cuya objetividad es puesta por el sujeto. Ulteriormente el ente se muestra como objeto de encargo (Bestand) ajustado a "aquel poner (Stellen) y encargar (Bestellen) respecto de la naturaleza que efectúa continuamente un inventario de las fuerzas arrebatadas a ella" ${ }^{57}$. En todos los casos acontece una decisión "sobre la historia o pérdida de la historia, esto es, sobre la pertenencia al ser o abandono en el noente (im Unseienden) ${ }^{\prime \prime 58}$.

En el proceso se mantiene una estructura unitaria que Heidegger pone de manifiesto en su conferencia "El peligro" (1949):

El traer en el modo de la phýsis es por ahora el poner-junto-a a partir de sí (das aus sich Beistellen), un poner (ein Stellen) que erige (aufstellt) lo presente a partir de sí en la condición-de-no-oculto. Phýsis, erigir a partir de sí (von sich her aufstellen) en lo no-oculto, es dejar venir a la presencia lo presente en la condición-de-no-oculto. [...]. De este modo se muestra tempranamente la phýsis, el traer delante que surge desde sí, con el carácter de un poner (Stellen) que no es una operación humana, sino que por el contrario aporta lo presente en cuanto tal al producir y representar (Her- und Vor-stellen) en la medida en que a la vez pone a disposición humana la condición-deno-oculto, esto es, trayendo y dando, proporciona un abrigar en la condición-de-nooculto. Pero este poner, el dejar durar y abrigar que trae delante a partir de sí, no tiene aún nada de los rasgos que muestra el esenciar del ser en aquel destino que lo hace acontecer como imposición (Ge-Stell). El poner en el modo de la im-posición que degrada y encarga esencia en un origen oculto $-y$ en un parentesco esencial con el poner en el sentido de la phýsis. ${ }^{59}$

\footnotetext{
55 Martin Heidegger, Beiträge zur Philosophie, p. 390.

${ }^{56}$ Ibidem, p. 135.

57 Martin Heidegger, Was heisst Denken? (1951-1952), Gesamtausgabe 8, Frankfurt am Main, Vittorio Klostermann, 2002, p. 238.

58 Martin Heidegger, Beiträge zur Philosophie, p. 100.

59 Martin Heidegger, Bremer und Freiburger Vorträge, Gesamtausgabe 79, Frankfurt am Main, Vittorio Klostermann, 1994, p. 64 s.
} 
Ahora bien, si una incipiente imposición o maquinación se encuentra ya en el comienzo, ¿no hay acaso una estructura a priori a la que está sujeto el ente más allá de que sea aprehendido desde sí mismo o en una relación condicionada por un sujeto? Si el resultado está implícito en el punto de partida, si el producir (Herstellen) final se encuentra emparentado con el erigir (Aufstellen) inicial de la phýsis, entonces la historia del ser reconoce un elemento fundante que pasa a través de ella como un invariante. El poner lo presente a partir de sí mismo en la condición-de-no-oculto y el poner en el modo de la imposición que degrada y encarga comparten un elemento común. Con otras palabras, un poner modalizable tanto en el dejar ser como en el imponer es una constante. Por tanto, el proceso que conduce a la génesis de un priori, ya sea en la forma de la idea platónica o de la objetividad kantiana, presupone él mismo un a priori.

Según Heidegger, el a priori que emerge en la historia del ser significa primero "la precedencia de la entidad respecto del ente", y se convierte luego, puesto que la idea platónica es "la raíz para la representación del a priori", en la "precedencia del representar". En lo que concierne al ser, Heidegger afirma: "La verdad del Ser y la esenciación del Ser no es ni lo anterior ni lo posterior" 60. Sin embargo, hemos advertido que hay algo más originario que las destinaciones del ser porque el Ereignis que destina se atiene a un a priori delimitado por un poner que, aunque sea definido en una de sus manifestaciones como un poder no-humano, siempre necesita una fundación humana, es decir, un tomar al vuelo la contraoscilación del Ereignis ingresando en ella. Si bien el poner y el hacer aparecer inherente a la phýsis no es una operación humana, el hombre es siempre aquel a quien atañe o concierne el venir a la presencia de modo que lo recibe como un don que se da. Es el centro de incidencia de ese poner que, inversamente, irradia también de él en la forma negativa de un dejar poner. $Y$ este dejar-ser no es otra cosa, en términos husserlianos, que una posición (Setzung) o una institución (Stiftung) de sentido y validez. Si las destinaciones comparten una misma estructura porque el poner de la técnica "reposa en el destino inicial del Ser (phýsis-thésis)" ${ }^{\prime 1}$ y por eso se puede hablar de "la relación de phýsis y tékhne y de la referencia de ambos a la condición-de-no-

${ }^{60}$ Martin Heidegger, Beiträge zur Philosophie, pp. 216, 222 s.
${ }^{61}$ Martin Heidegger, Bremer und Freiburger Vorträge, p. 66. 
oculto" $^{\prime 62} \mathrm{y}$, además, el hombre no puede dejar de ser "el constante receptor"63 del don, entonces una estructura invariante regula tanto la articulación como la recepción del aparecer. Si hay un poner en el surgir-desde-sí de la phýsis, habrá que ver en el erigir (Aufstellen) del comienzo una institución que el hombre deja acontecer, que da lugar a un proceso de sedimentación, reactivación y transformación de sentidos, y que puede ser moldeado de múltiples maneras hasta llegar a la imposición final. Este movimiento no solo está regido por una "estructura a priori" ${ }^{64}$ sino que nos coloca en el terreno de una estructura trascendental.

\section{LA DECISIÓN EN HUSSERL: INSTITUCIÓN DE UN HORIZONTE HISTÓRICO}

Analizamos ahora el tema de la decisión en la versión de Husserl teniendo en cuenta la siguiente observación contenida en un manuscrito cuatro años posterior a la publicación de Ser y tiempo:

La comprensión del ser es algo completamente vacío mientras no la reconozcamos [...] como apercepción del mundo en su respectiva estructura trascendental determinada como una estructura constante que se repite de un modo invariante, y entonces nos formulemos en relación con ella los problemas esenciales, entre ellos la pregunta fundamental por la estática y la eventual génesis de esta apercepción universal. ${ }^{65}$

En este texto de Husserl se encuentra, además de la referencia a un a priori, cuya presencia en Heidegger se ha intentado mostrar en el apartado anterior, la referencia a una dimensión trascendental, de la que nos ocupamos de inmediato a fin de mostrar que este camino trascendental no es, como afirma Heidegger, "solo provisorio" 66.

\footnotetext{
62 Martin Heidegger, Heraklit, Gesamtausgabe 55, Frankfurt am Main, Vittorio Klostermann, 1979, p. 202.

63 Martin Heidegger, Zur Sache des Denkens, p. 16.

64 Edmund Husserl, Die Krisis der europäischen Wissenschaften und die transzendentale Phänomenologie, Husserliana VI, Den Haag, Martinus Nijhoff, 1962, p. 378.

${ }^{65}$ Edmund Husserl, Die Lebenswelt. Auslegungen der vorgegebenen Welt und ihrer Konstitution. Texte aus dem Nachlass (1916-1937), Husserliana XXXIX, Dordrecht, Springer, 2008, p. 490.

${ }^{66}$ Martin Heidegger, Beiträge zur Philosophie, p. 305. Klaus Held observa que Heidegger plantea la cuestión del ser sobre una base extrafenomenológica con referencia a argumentos no-fenomenológicos que surgen de la influencia de Aristóteles. Considera que lo que importa es el horizonte universal del mundo como una dimensión predada de patencia. No obstante, opone esta dimensión al análisis de Husserl porque le atribuye una identificación de la vida trascendental con la inmanencia de la conciencia. Cfr. Klaus Held, "Heidegger und das Prinzip der Phänomenologie", en Annemarie Gethmann-Siefert y Otto Pöggeler (eds.), Heidegger und die praktische Philosophie, Frankfurt am Main, Suhrkamp, 1988, p. 116 ss. En contraste con este punto de vista, hemos mostrado que, para Husserl, conciencia y mundo
} 
El yo husserliano articula de variada manera, en un segundo giro que sigue al primero motivado por la afección hylético, una forma temporal que también le es entregada para que la introduzca en horizontes temporales más complejos. Sobre la protensionalidad instintiva, según Husserl, se edifican formaciones superiores que implican fines en sentido estricto. Una protoforma aparece, pues, como un segundo abismo que requiere también una complementación a través de la intencionalidad yoica o intencionalidad de la voluntad a la que se refiere el mencionado manuscrito sobre "Teleología universal". Veamos, pues, el carácter de "la decisión (Entschluss) en favor de un horizonte temporal"67. Husserl subraya que no se debe pasar por alto "el fundamental doble paso (Doppelschritt) de la constitución como constitución progresiva y regresiva" ${ }^{\prime 68}$. En este doble paso se ponen en juego "diferentes 'temporalizaciones' y 'temporalidades'", esto es, "estratos en los cuales se repite el juego de la temporalización" ${ }^{\prime 69}$.

En la constitución progresiva, la vida trascendental avanza hacia el futuro e incorpora las adquisiciones de cada nuevo presente. Este tipo de constitución convierte al yo en un ser histórico, y permite considerar el tiempo como una formación espiritual: que se configura en el desarrollo humano y da lugar a un ordenamiento temporal. Una generatividad específicamente espiritual se instituye como generatividad de orden superior mediante la institución de metas comunes de largo alcance. Cuando mi presente y sus horizontes temporales coinciden con el presente de los otros y sus horizontes, se constituye "un a la vez temporal de tiempo supramonádico o intermonádico de nivel superior" con el "pasado, el copresente y el futuro comunitarios" ${ }^{\prime 70}$, sus modos particulares de darse en cada uno de los sujetos, e intenciones que se originan en el presente de un sujeto pero alcanzan su cumplimiento en el presente de otro. Las metas permanentes dan lugar a un "lapso de tiempo entre el 'yo quiero' instituyente y

forman una unidad originaria, y que, por tanto, la vida trascendental presupone una dimensión de patencia en aquello a lo que esa misma vida, en tanto conciencia intencional, se vuelve para convertirlo en su correlato.

67 Edmund Husserl, Die Krisis der europäischen Wissenschaften und die transzendentale Phänomenologie. Ergänzungsband aus den Nachlass 1934-1937, Husserliana, XXIX, Dordrecht/Boston/ London, Kluwer Academic Publishers, 1993, p. 371. Husserl aclara de inmediato que "me decido, ya sea en una decisión (Entscheidung) sobre creencia, una decisión sobre valores o una decisión de la voluntad" (p. 372).

${ }^{68}$ Edmund Husserl, Die Lebenswelt, p. 505.

${ }^{69}$ Ibidem, pp. 558, 561.

70 Edmund Husserl, Zur Phänomenologie der Intersubjektivität III, p. 343; Die Krisis. Ergänzungsband, p. 5. 
la realización, $[\ldots]^{\prime 71}$. Al describir la peculiar estructura temporal de la voluntad, Husserl señala que el primer ahora tiene como punto de partida creador un horizonte de futuro creador y se modifica en un horizonte de pasado creador. El ahora aparece "como llegado a ser a partir de un fiat, como producido"72. A cada punto ahora de la serie temporal es inherente no solo una fase eminente que corresponde la originalidad creadora de la voluntad sino un doble horizonte de pasado y de futuro compuesto por modificaciones de la voluntad, y en el que el progresivo acortamiento del horizonte de futuro tiene su reverso en la correspondiente prolongación del horizonte de pasado. Como los momentos de la voluntad brotan uno del otro, también los momentos del tiempo fluyen activamente uno a partir del otro: "Cada nuevo continuo de la voluntad en el pasaje del ahora al nuevo ahora emerge fluyendo del anterior no como en la originaria conciencia del tiempo el ahora emerge fluyendo del ahora pasado, sino que más bien surge de él en virtud de la propia creación de la voluntad"73. Así, la voluntad y sus metas producen una serie temporal plenificada en un ordenamiento vital volitivo: "También para la comunidad hay un orden de su vida comunitaria que comprende toda su temporalidad a partir de una voluntad comunitaria, $[\ldots]^{\prime \prime 74}$.

La constitución regresiva tiene lugar por medio de aprehensiones o apercepciones históricas que reconstruyen el pasado. Puedo efectuar una síntesis de mi continuidad rememorativa con los recuerdos de otros. Puedo recordar "en otros", esto es, evocar un "'recuerdo' por medio de los otros, de los otros de los otros, etc. ${ }^{\prime 75}$. En este proceso es posible ir más allá del alcance del recuerdo y hacer intuitivo el pasado en intuiciones que no tienen el carácter de rememoraciones en que percepciones previas efectivas son recordadas, sino el carácter de intuiciones en las que me represento algo como si lo hubiera experienciado cumpliendo con las condiciones de la transferencia aperceptiva por analogía. Sucesivamente podemos colocarnos en el lugar de i) los antepasados con los cuales nos encontramos en un nexo generativo, ii) aquellos hombres con cuya generatividad no podemos establecer un nexo, y iii) los animales de épocas

${ }^{71}$ Edmund Husserl, Die Krisis. Ergänzungsband, p. 366 n.

72 Edmund Husserl, Vorlesungen über Ethik und Wertlehre 1908-1914, Husserliana XXVIII, Dordrecht/Boston/London, Kluwer Academic Publishers, 1988, p. 110.

${ }^{73}$ Ibidem, p. 111.

${ }^{74}$ Edmund Husserl, Die Lebenswelt, p. 523 n.

${ }^{75}$ Ibidem, p. 501. 
pasadas que también han tenido una experiencia del mundo. Así, se produce una constitución de tiempos inaccesibles por medio de la idealización de la capacidad de información mediada por los otros. Además, se retrocede mucho más allá de lo que han constituido las generaciones por medio de la reconstrucción de un tiempo que ni los hombres ni los animales han experienciado. Husserl se ocupa de la ampliación del mundo circundante hacia una naturaleza universal en lo infinito con "un tiempo infinito como forma -una forma que también puede ser vacía"76. La típica de las causalidades naturales de nuestro mundo presente se transfiere analógicamente a las épocas de la historia de la tierra en que era imposible la vida humana y animal, y, con el desarrollo de la paleontología, la geología y la astronomía, enlazadas con la física exacta, la ampliación de la historia natural continúa en dirección al tiempo astronómico.

Tanto el movimiento progresivo como el regresivo presuponen estructuras omniabarcadoras que posibilitan la unidad del tiempo histórico y nuestro movimiento en él. Husserl afirma que obro "como si tuviera una capacidad de movimiento a través de todos los tiempos"77. Además, llama la atención sobre los "comienzos de nuevas dimensiones de la temporalización, esto es, del tiempo con su contenido", y señala que "todos estos tiempos acceden sintéticamente a la unidad de un tiempo"78. Esta forma, que está presupuesta por todas las temporalidades, comprende un continuo de lugares, la sucesión y la simultaneidad, la duración y el horizonte de los fenómenos temporales. El tiempo se muestra como la forma del mundo en tanto totalidad de las cosas, es decir, como "la forma universal, que comprende en sí todas las temporalidades particulares: todos los tiempos particulares coinciden y constituyen por coincidencia un único tiempo, $[\ldots]^{\prime \prime 79}$. Es importante tener en cuenta que la forma del tiempo no es meramente forma de lo ya conocido sino también del horizonte de cosas desconocidas. La participación en una misma forma, y la apertura de esta en tanto horizonte vacío, permiten la inserción una en otra de temporalidades y su convergencia en una temporalidad de orden superior. Solo el único mundo con su

\footnotetext{
${ }^{76}$ Edmund Husserl, Die Lebenswelt, p. 303. Cfr. p. 512, y Edmund Husserl, Späte Texte über Zeitkonstitution, p. 443.

${ }^{77}$ Edmund Husserl, Zur Phänomenologie der Intersubjektivität III, p. 239.

78 Edmund Husserl, Die Krisis der europäischen Wissenschaften und die transzendentale Phänomenologie, Husserliana VI, Den Haag, Martinus Nijhoff, 1962, p. 172.

${ }^{79}$ Edmund Husserl, Späte Texte über Zeitkonstitution, p. 298. Cfr. Elisabeth Ströker, "Zeit und Geschichte in Husserls Phänomenologie. Zur Frage ihres Zusammenhangs", en E. S., Phänomenologische Studien, Frankfurt am Main, Vittorio Klostermann, 1987, p. 158.
} 
única forma temporal y su horizonte vacío que trasciende todo tiempo plenificado posibilita las relaciones entre las diferentes temporalidades. A pesar del conflicto que se produce entre temporalidades de contenido determinado precisamente en razón de esta determinación, los procesos transcurren "en indeterminaciones horizónticas y en el uno-en-otro intencional de los horizontes" ${ }^{\prime 80}$, es decir, con la incorporación recíproca y entramado de temporalidades diversas. La indeterminación funciona como base para la convergencia de horizontes temporales en una unidad superior.

Por consiguiente, la forma del tiempo implica para Husserl, más allá de la temporalidad subyoica, y como estructura que se configura a partir de ella, una segunda yección de la pasividad que es retomada en una respuesta o proyección activa por el yo de la voluntad. Por un lado, el abismo indiferenciado inherente al horizonte inicial originario se articula en una forma temporal. Sin un yo que se vuelve hacia la pretemporalización hylética y reflexiona sobre este volverse, no se destaca la forma del tiempo como forma para contenidos hyléticos siempre nuevos. Por otro lado, el abismo indiferenciado inherente al horizonte marginal de afección nula es un trasfondo vacío que funciona como factor de unidad y síntesis para las temporalidades que lo plenifican. Sin un yo que introduzca contenidos en la forma, no se configuran temporalidades diversas. En tanto vacía o indeterminada, esta forma se puede ordenar y determinar de variadas maneras. Cuando el mundo es considerado solo como un horizonte vacío e indeterminado, se lo ha de caracterizar como carente de un ordenamiento temporal ${ }^{81}$.

\section{LA INSTANCIA ÚLTIMA}

Una vez considerada la temporalidad primigenia y la respuesta a su interpelación podemos volvernos hacia la instancia última que opera entre ambas

\footnotetext{
${ }^{80}$ Edmund Husserl, Späte Texte über Zeitkonstitution, p. 278.

${ }^{81} \mathrm{Cfr}$. Ibidem, p. 192. Pilar Fernández Beites ha puesto de relieve críticamente que, en el viraje heideggeriano, "[e]l tiempo no es ya en ningún sentido el tiempo de un sujeto, sino un tiempo asubjetivo, que solo reposa en un acontecimiento (Ereignis) apersonal en el que está contenida toda posible apropiación o propiedad. La supuesta propiedad del hombre no reside en su subjetividad, o en su ser 'sí mismo', según la expresión del primer Heidegger, sino que reposa ya definitivamente en un apropiarse impersonal" (Tiempo y sujeto. Después de Heidegger, Madrid, Encuentro, 2010, p. 321).
} 
para señalar nuevas convergencias ${ }^{82}$. Esa instancia última es para Husserl el presente viviente y para Heidegger el Ereignis. Husserl caracteriza al presente viviente como "el 'protofenómeno' al que conduce retrospectivamente toda pregunta retrospectiva trascendental en el método de la reducción fenomenológi$\mathrm{ca}^{\prime 83}$. Y Heidegger afirma: "No hay otra cosa a la que remita aún el Ereignis, a partir de la cual pueda ser explicado"84. Más allá de la reducción desde los objetos a la conciencia, la misma vida trascendental debe ser mostrada, en una reducción radicalizada, como el resultado de la temporalización que se lleva a cabo a partir del presente viviente enlazado con el protoyo (Ur-ich) y la protovida (Ur-Leben) trascendental. En el plano ya no de la génesis que tiene lugar desde un preyo, sino de la fundamentación, la reducción radicalizada nos retrotrae a un protoyo que no precede temporalmente sino que es un origen permanente en tanto todo experienciar y obrar remite en última instancia a su presente viviente. Por su parte, luego del salto que tiene lugar desde los entes en dirección al ser concebido como fundamento, Heidegger se refiere a un salto que va desde el ser hacia un abismo en que opera el Ereignis que se diferencia de todo suceso que remita a otra instancia explicativa.

Heidegger llega al Ereignis como aquello que da tiempo y ser. Que la donación del ser repose en la donación del tiempo no significa, para Heidegger, que el tiempo sea aquello que da el ser sino que uno y otro reposan "a una" en el Ereignis. Heidegger afirma que el Ereignis ha de ser pensado de tal manera que "no puede ser fijado ni como ser ni como tiempo" a pesar de que en él se piensan a la vez ambos modos del dar y por ende "en cierta manera también ser y tiempo quedan en pie $^{\prime 85}$. Por su parte, Husserl llega también al presente viviente como la instancia última en cuyo protoser (Ursein) o preser (Vor-Sein) y en cuyo protiempo (Urzeit) o pretiempo (Vor-zeit) reposa el darse del tiempo y del mundo. Sostiene que "tiempos, objetos, mundos de todo sentido tienen en última instancia su origen en el protofluir del presente viviente" ${ }^{\prime 16}$. La permanencia y carácter pretemporal del presente viviente se enlaza con presentes pasajeros que fluyen a través de él y se unifican en un único tiempo por la ana-

${ }^{82}$ He desarrollado más extensamente esta cuestión en "Modos del acontecimiento", en Aníbal Fornari y Patricio Perkins (comps.), Tiempo y acontecimiento, Buenos Aires, Biblos, 2010, pp. 19-44.

${ }^{83}$ Edmund Husserl, Späte Texte über Zeitkonstitution, p. 6.

84 Martin Heidegger, Unterwegs zur Sprache, p. 247.

${ }^{85}$ Martin Heidegger, Zur Sache des Denkens, p. 53.

${ }^{86}$ Edmund Husserl, Späte Texte über Zeitkonstitution, p. 4. Cfr. pp. 6, 12, 187, 269, 342, 350. 
logía de la forma o la asociación formal, y en este proceso se constituye el mundo sobre la base del contenido hylético de cada presente y sus evocaciones en virtud de la analogía de la plenitud o asociación del contenido ${ }^{87}$.

El paralelo se extiende a otros aspectos del tiempo y el mundo. Heidegger afirma que "lo propio del tiempo-espacio del auténtico tiempo", al que remite la temporalidad extática del Dasein, reposa en el juego que asigna (Zuspiel) las dimensiones temporales unas a otras, esto es, en el "alcanzarse uno-a-otro (Einander-sich-reichen) de futuro, haber-sido y presente" ${ }^{\prime 88}$. Se trata de la primera dimensión del tiempo a partir de la cual se han de pensar las tres restantes. Así como Heidegger se ocupa de un juego que asigna unas a otras las dimensiones temporales, subyace a ellas como primera dimensión y es un don del Ereignis, Husserl analiza un protofluir (Urströmen) que se manifiesta como pasar fluyendo (Verströmen), fluir-desde (Abströmen) y fluir-hacia (Zuströmen) en un "fluyente a la vez" que se centra en el presente viviente como "un presente pluridimensional" ${ }^{89}$. Mientras que el Ereignis se muestra como la recíproca oscilación o contrabalanceamiento entre el ser que necesita del Dasein y el Dasein que pertenece al ser, el presente viviente se exhibe como el punto medio, la copertenencia contraoscilante, en que las motivaciones o interpelaciones que proceden del mundo se unen con el volverse-hacia, responder y obrar del yo. Husserl se ocupa del "protoacontecer (Urgeschehen) de la subjetividad trascendental" que impulsa y es condición de posibilidad del acontecer de la vida de la conciencia y del acontecer del mundo, es decir, del "acontecer de una pluriforme estructura del acontecer" ${ }^{\prime 90}$.

Una coincidencia se advierte también en torno de la unicidad que caracteriza a la instancia última. Heidegger aclara que utiliza la palabra Ereignis como un singulare tantum porque lo que nombra "acontece solo en lo singular o más bien ni siquiera ya en un número sino de una manera única" ${ }^{91}$. Además, al Ereignis no se le pueden aplicar las habituales relaciones de ordenación, y colocar bajo suyo aquello que se da como un don, porque no es ni un "universal

\footnotetext{
${ }^{87}$ Cfr. Ibidem, p. 296.

88 Martin Heidegger, Zur Sache des Denkens, p. 19.

89 Edmund Husserl, Späte Texte über Zeitkonstitution, p. 129. Cfr. p. 58.

${ }^{90}$ Edmund Husserl, Edmund Husserl, Zur phänomenologischen Reduktion, p. 298; Späte Texte über Zeitkonstitution, p. 5.

${ }_{91}$ Martin Heidegger, Identität und Differenz (1955-1957), Gesamtausgabe 11, Frankfurt am Main, Vittorio Klostermann, 2006, p. 45.
} 
apartado" ni un "concepto superior"92. Análogamente, Husserl se refiere al presente viviente como único porque es un protomodo en contraste con los modos derivados que configuran una multiplicidad de unidades singulares. Se trata de una unicidad que se reitera o pluraliza en los presentes pasajeros sin perder ese carácter. El presente viviente no puede ser calificado como singular o plural sino que es la condición de todos los presentes constituidos en tanto singulares o plurales. No es un presente singular entre otros presentes singulares, es decir, algo singular dentro de una pluralidad, y en este sentido existe en una unicidad para la cual el plural carece de sentido.

El Ereignis se sustrae en favor de lo que se da. Por eso el Ello en el Ello da (Es gibt) "permanece indeterminado, enigmático, y nosotros mismos permanecemos perplejos"93. Nunca podemos colocarlo delante de nosotros en un estarfrente (ein Gegenüber), y por eso "es retenido en lo no dicho (im Ungesagten), permanece como lo no mostrable (Unzeigbares) en lo oculto, es misterio" ${ }^{\prime 94}$. A su vez, el presente viviente es el presente en que el yo opera anónimamente como "protoyo", es decir, no como el yo que es objeto de la reflexión sino el yo que reflexiona y al que se da el yo en cuanto objetivado. Resulta inexpresable porque el presente sobre el que se reflexiona ya no es el presente desde el que se reflexiona: "En cuanto preser es inexperienciable, indecible (Es ist als VorSein unerfahrbar, unsagbar); [...]"

Resumiendo. He trazado un paralelo entre el abismo heideggeriano y el horizonte inicial originario husserliano en tanto encierran un tiempo-espacio que requiere para desplegarse, como operación complementaria, la fundación del Dasein o el volverse-hacia de la subjetividad trascendental. Esta operación se diferencia en tanto queda enlazada para Heidegger con la historia del ser y para Husserl con la apercepción del mundo y su constitución progresiva y regresiva. No obstante, la contraoscilación entre ser y Dasein, o entre mundo y subjetividad, se despliega a través de una instancia última que vuelve a exhibir rasgos coincidentes. Se ha de recordar que, en sus Notas de trabajo, MerleauPonty se refiere a "lo que quiere decir la Offenheit de Husserl o la Verborgen-

\footnotetext{
92 Ibidem, p. 46; Martin Heidegger, Zur Sache des Denkens, p. 27.

${ }^{93}$ Ibidem, p. 22.

94 Martin Heidegger, Unterwegs zur Sprache, p. $241 \mathrm{s.}$

95 Edmund Husserl, Späte Texte über Zeitkonstitution, p. 269.
} 
heit de Heidegger", los considera "como Offenheit, como Verborgenheit del Ser", y enlaza la cuestión con el tema de "la estructura misma del horizonte" y el "Überstieg hacia el horizonte" ${ }^{\prime 96}$. Además, alude al carácter abismal del fundamento que, en su caso, es una carne del cuerpo que funda y a la vez se prolonga en la carne del mundo. En virtud de esta prolongación, "el pretendido Grund es Abgrund" ${ }^{\prime 97}$. La carne implica una abismal pregnancia de posibilidades al igual que el horizonte inicial originario de Husserl o el abismo de Heidegger.

Traducido por Francisco Conde Soto 